\title{
南海与太平洋表层水温卫星遥感资料的 子波频谱分析
}

\section{许金山 田纪伟 魏恩泊}

(青岛海洋大学物理海洋教育部重点开放实验室, 青岛 266003. Email: lab@ mail.ouqd.edu.cn)

摘要 通过对 1982 1999 年美国国家海洋与大气管理局高级甚高分辨率辐射计(NOAA/AVHRR) $1^{\circ} \times 1^{\circ}$ 海表周平均温度 $(\mathrm{SST})$ 遥感资料的分析, 发现南海 SST 异常存在大约 4 年与 8 年尺度的振荡 周期, 赤道东太平洋与赤道西太平洋 SST 异常分别存在着大约 4 年尺度、8 年尺度振荡周期. 通 过子波分析方法的多尺度特性, 明显地发现在 4 年尺度周期上, 南海与赤道东太平洋的 SST 异常 发生同相耦合振荡, 并且每次发生在东太平洋的厄尔尼诺与拉尼娜现象, 南海都会与之响应. 而 在 8 年尺度周期上, 南海与赤道西太平洋的 SST 异常明显相关.

\section{关键词 海表温度异常 南海 太平洋 厄尔尼诺 子波变换 遥感}

海洋大气系统的年际循环是气候变化中很强的信号之一, 而且海洋大气的长周期变化特征 与全球气候异常密切相关, 因而越来越引起科学家的广泛关注. 在影响年际尺度气候变化的诸 多因子中, 来自海洋的厄尔尼诺-拉尼娜是目前了解较为清楚的一个强信号. 赤道太平洋海面温 度的异常增暖是厄尔尼诺现象的一个最基本特征, 作为海洋热力状态重要标志的 SST 研究, 尤 其是对海面温度异常 (SSTA)的研究, 已成为当前全球变化和区域性气候中的重要问题. 而南海 是西太平洋面积最大的一个边缘海, 南海与太平洋之间的热力-动力学相互关系到底是怎样发 生、又有何种关系一直是人们普遍关心的问题. 周发琇等人 ${ }^{[1,2]}$ 依据功率谱分析、数字滤波等方 法, 研究得出南海水温低频振动是热带太平洋水温低频振动的组成部分. 钮智旺 ${ }^{[3]}$ 依据 SST 的 月平均资料, 利用功率谱分析, 研究我国南海西沙与秘鲁及厄瓜多尔外海表层水温的关系, 发 现它们均存在一个 3.3 年的长周期变化. 谢强等人 ${ }^{[4]}$ 也利用谱分析方法研究并发现南沙与暖池 海域 SST 周期约为 16.6 年的同相低频耦合振荡. 以上分析皆是借助于谱分析的方法, 因此无法 从空间上识别南海与太平洋之间的振荡关系. 并且所用资料均是站点观测资料, 所以难以代表 南海海域及太平洋海域的整体特征. 因此, 通过对大范围、长时间、高分辨卫星遥感资料分析, 在广延空间结构上探索或揭示南海与赤道太平洋 SST 的相互关系, 无疑是十分必要的.

本文通过对 1982 1999 年 NOAA/AVHRR 辐射计遥感资料 $1^{\circ} \times 1^{\circ}$ 经纬网格的南海及赤道 太平洋地区周平均 SST 资料分析, 运用子波分析时频分辨、多尺度的特性, 进一步从不同频 率尺度揭示二者之间的确切关系, 有助于深入研究南海海气相互作用和太平洋地区海洋大尺 度环流的相互关系.

\section{1 南海与太平洋 SSTA 的时间序列}

海洋遥感卫星资料大范围、长时间、高分辨的特性, 为研究海洋的空间与时间结构提供了大 量、高质量的数据. 本文利用 NOAA 卫星辐射计的周平均 SST 资料, $1^{\circ} \times 1^{\circ}$ 经纬网格, 时间从 1982 年 1 月 1999 年 1 月. 将所研究区域分为 3 部分: 南海海域 $\left(105^{\circ} \mathrm{E} \sim 125^{\circ} \mathrm{E}, 5^{\circ} \mathrm{N} 25^{\circ} \mathrm{N}\right)$ 、赤道东太 平洋 $\left(150^{\circ} \mathrm{W} \sim 90^{\circ} \mathrm{W}, 15^{\circ} \mathrm{S} \sim 15^{\circ} \mathrm{N}\right)$ 、赤道西太平洋 $\left(130^{\circ} \mathrm{E} \sim 180^{\circ} \mathrm{E}, 15^{\circ} \mathrm{S} \sim 15^{\circ} \mathrm{N}\right)$, 利用温度平均值来 
表示所选海区的平均温度状况, 图 1(a), 2(a)和 3(a)分别是南海、赤道东太平洋和赤道西太平 洋 SSTA 异常区域平均后得到的时间序列数据, 从图中可以较明显地看到它们的年振 荡周期. 这种年循环特征无疑是气候变化中最强的信号之一. 观测研究认为, 有着年周期的气 候系统季节特征是由于季节性变化的太阳辐射所驱动, 这是为人们所熟悉的. 在这里我们

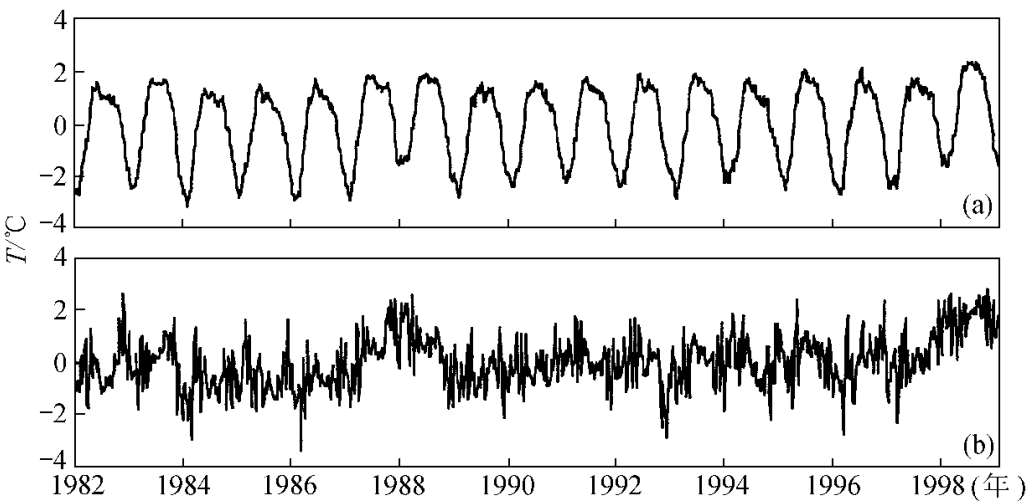

图 1 南海海域海表温度异常 (a)和去除年周期后南海海域海表温度异常(b)

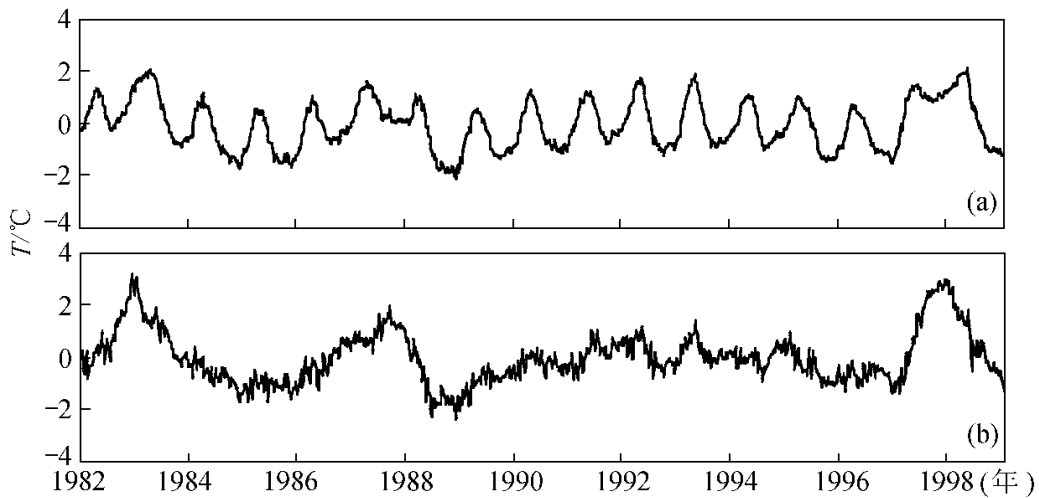

图 2 赤道东太平洋海域海表温度异常(a)和去除年周期后赤道东太平洋 海域海表温度异常 (b)

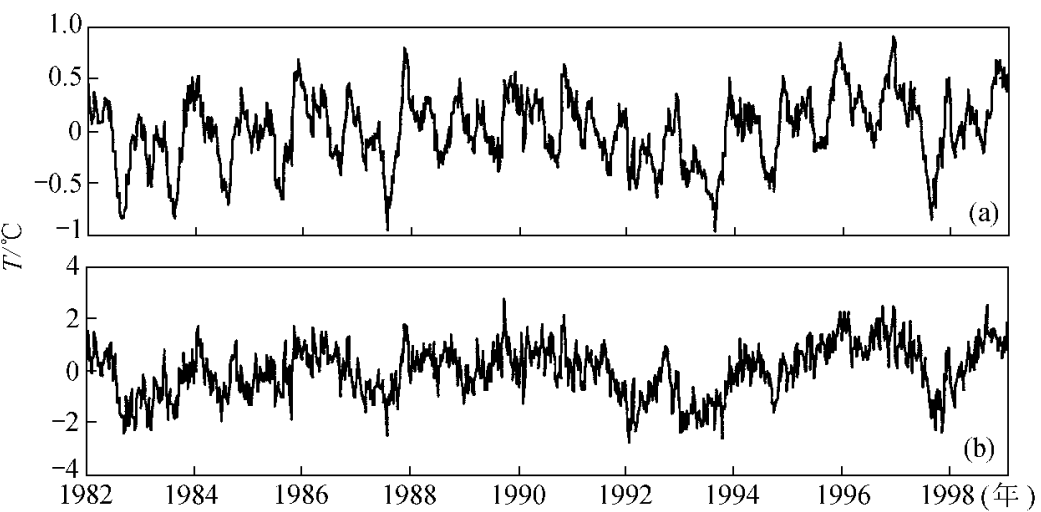

图 3 赤道西太平洋海域海表温度异常 (a)和去除年周期后赤道西太平洋海 域海表温度异常 (b) 
更关心的是所研究海域去除年周期 SSTA 后的长周期变化. 图 1(b), 2(b)和 3(b)分别是通过滤 波并去掉年周期信号后温度异常的时间序列. 以下 SSTA 均代表去除年周期后的海表温度异常.

\section{2 南海与太平洋海表温度的时频分析}

子波分析已广泛应用于研究不同时间尺度气候要素变化的特征 ${ }^{[5 \sim 7]}$, 根据子波分析的定 $义^{[8]}$, 我们采用以 Morlet 子波基的子波变 换来分析上述信号，根据子波频谱的定义 ${ }^{[9]}$, 首先给出南海、赤道东太平洋和赤道西太 平洋 SSTA 的子波频谱. 从图 4 中可以看 到, 在去掉年振荡周期后, 南海 SSTA 分别 存在 $3 \sim 5$ 和 8.5 年左右两个主要的振荡周 期, 赤道东太平洋主要的振荡周期为 3 5 年, 赤道西太平洋则存在一个明显较强的 8 年左右的长振荡周期, 而 3 5 年的振荡则 相对要小得多. 如果说南海与赤道东太平 洋存在一个共同的振荡周期的话, 那么它
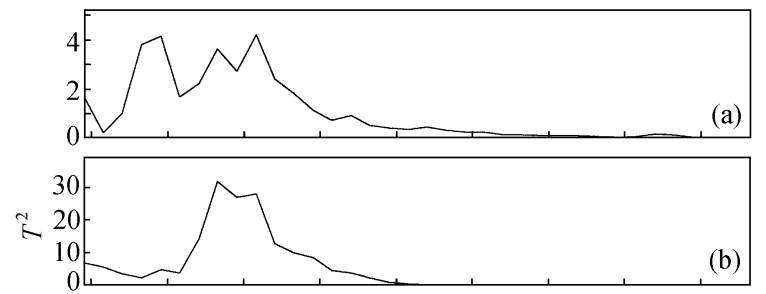
应该是 3 5 年的长振荡周期. 同样, 值得

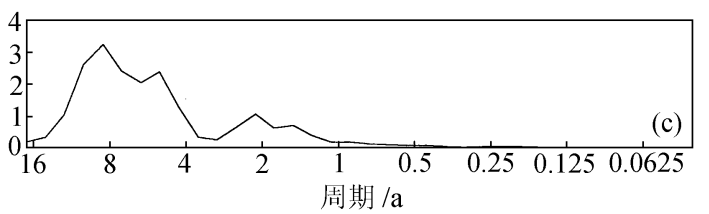

图 4 SSTA 的子波频谱

(a) 南海海域, (b) 赤道东太平洋海域, (c) 赤道西太平洋海域 注意的是南海存在的 8.5 年长振荡周期正好与赤道西太平洋的周期相近. 以往的分析, 难以在 时空结构上刻画它们这种相互关系. 子波变换系数的实部(振幅)能显示脉动的强弱分布 ${ }^{[8,10]}$, 子波分析时频分辨的特点, 使得我们能够同时从时间和频率结构上观察这种强弱分布的变化. 图 5 是根据子波变换得到的子波变换系数的实部时频结构图, 图中的明暗代表 SSTA 变化的

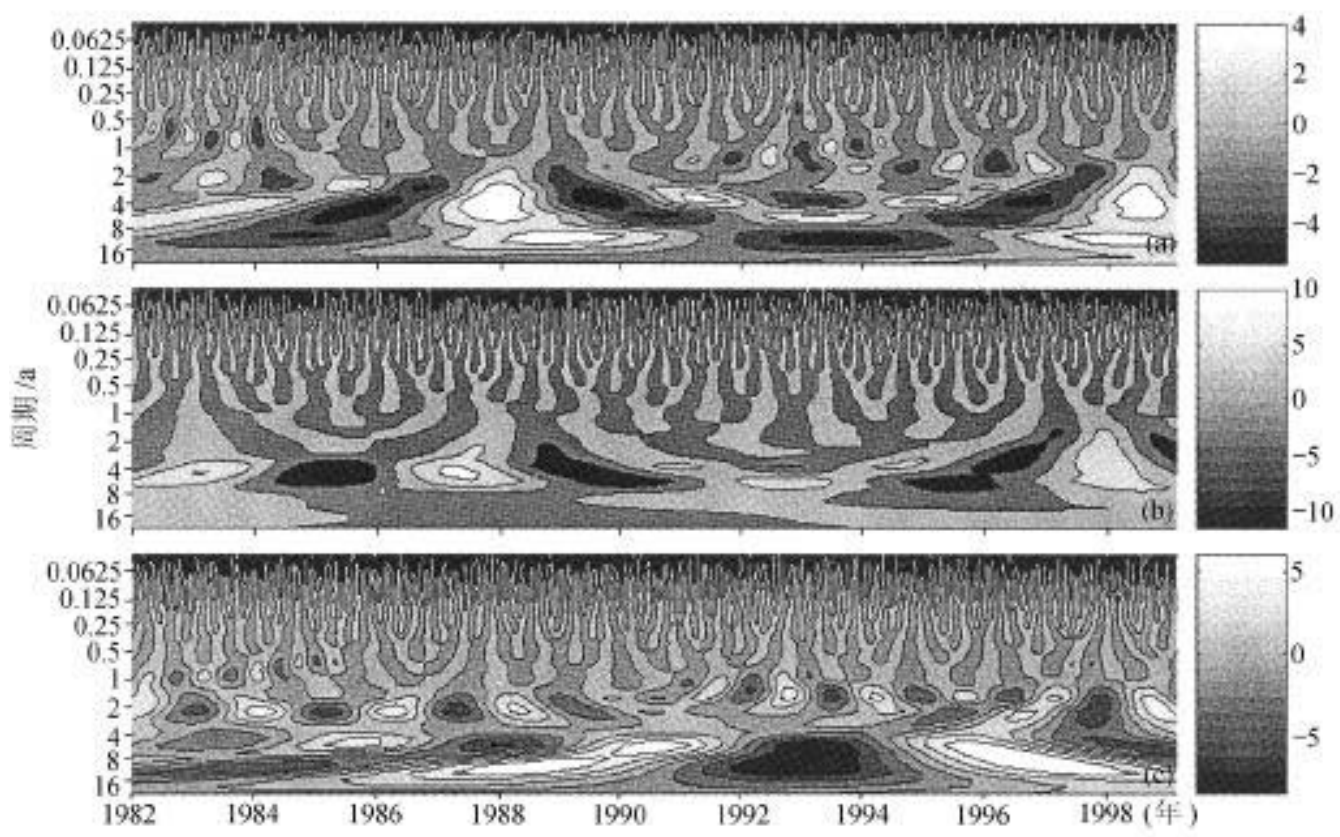

图 5 SSTA 的子波变换系数实部时频结构图

(a) 南海海域, (b) 赤道东太平洋海域, (c) 赤道西太平洋海域 
强弱分布，黑色代表低温异常，白色代表高温异常.

从图 5 中也可以看到在图 4 中子波频谱所体现的特征. 另外, 赤道东太平洋的 SSTA 是 厄尔尼诺事件发生的重要标志, 人们已把这些海区的 SSTA 作为厄尔尼诺事件发生强度的指 标 ${ }^{[3]}$. 从图 5(b)可以明显的观察到 4 年左右尺度的冷暖异常交替. 其中, 可以明显地看到其对 应的 1982 1999 年 4 次高温异常, 即厄尔尼诺年: 1982 1983, 1987 1988, 1993, 1997 1998 年; 同样也可以看到 3 次低温异常, 即拉尼娜年: 1985，1989 1990，1995 1996 年. 而从图 5(a)中 $4 \sim 5$ 年左右的尺度上, 可以看到在东太平洋每次冷暖交替发生后, 南海就会相应地发生, 只是 略微滞后大约半年左右. 而在西太平洋(图 5(c)), 在同样尺度下, 其变化与东太平洋正好是反 位相的, 但也稍微滞后半年左右, 正好与南海的冷暖交替基本同步. 为能更清楚地观察这一现 象, 将图 5 中平均尺度为 $4 \sim 5$ 年的变化提取出来, 表示在图 6 上.

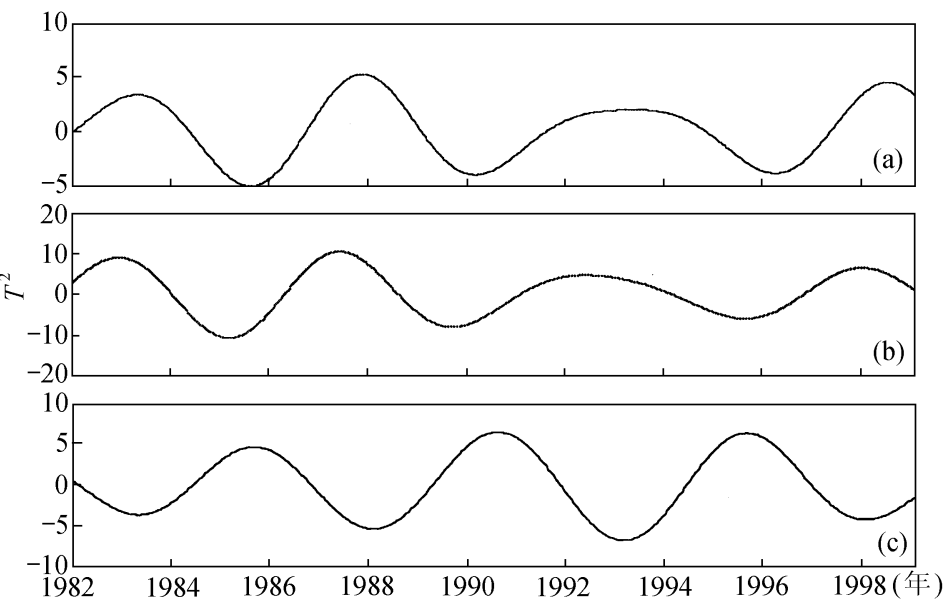

图 6 SSTA $4 \sim 5$ 年平均尺度特征

(a) 南海海域, (b) 赤道东太平洋海域, (c) 赤道西太平洋海域

从南海和赤道东太平洋温度异常的 4 5 年尺度特征(图 6), 可以看到在 1982 1999 年之间 共有 4 次高温异常, 这就是前面提到的厄尔尼诺事件, 在赤道东太平洋分别对应于 1982 年 12 月、1987 年 6 月、1992 年 5 月和 1997 年 12 月, 而在南海 4 个高温异常则分别对应于 1983 年 5 月、1 1987 年 11 月、 1993 年 2 月和 1998 年 6 月. 可见南海也受到发生在东太平洋的厄尔 尼诺事件影响, 强度较赤道东太平洋弱一些, 而且有些滞后, 滞后的时间分别为 5,6,8 和 7 个月. 图 6(b)中, 赤道东太平洋海表温度所对应的 3 次低温异常时间分别为 1985 年 3 月、1989 年 9 月和 1995 年 8 月, 这正好对应着 1982 1999 年之间发生在太平洋的拉尼娜现象, 而南海 的响应时间分别为: 1985 年 8 月、1990 年 2 月和 1996 年 3 月, 滞后时间分别为 6,6 和 8 个 月. 对于西赤道太平洋, SSTA 的趋势则与赤道东太平洋相反, 见图 6(c).

从子波频谱图上, 我们已经注意到南海与赤道西太平洋在 $8 \sim 10$ 年尺度周期上都存在能量 的集中分布. 图 7 是将图 5 中平均尺度为 $8 \sim 10$ 年周期的变化提取出来的结果. 图 7(a)与(c)分 别反映南海与赤道西太平洋 SSTA 8 10 年周期尺度的变化, 可见二者的变化趋势十分一致, 呈同相耦合振荡, 而赤道东太平洋 SSTA(图 7(b))则与赤道西太平洋 SSTA 呈反相变化. 赤道 西太平洋 SSTA 的强度最大. 

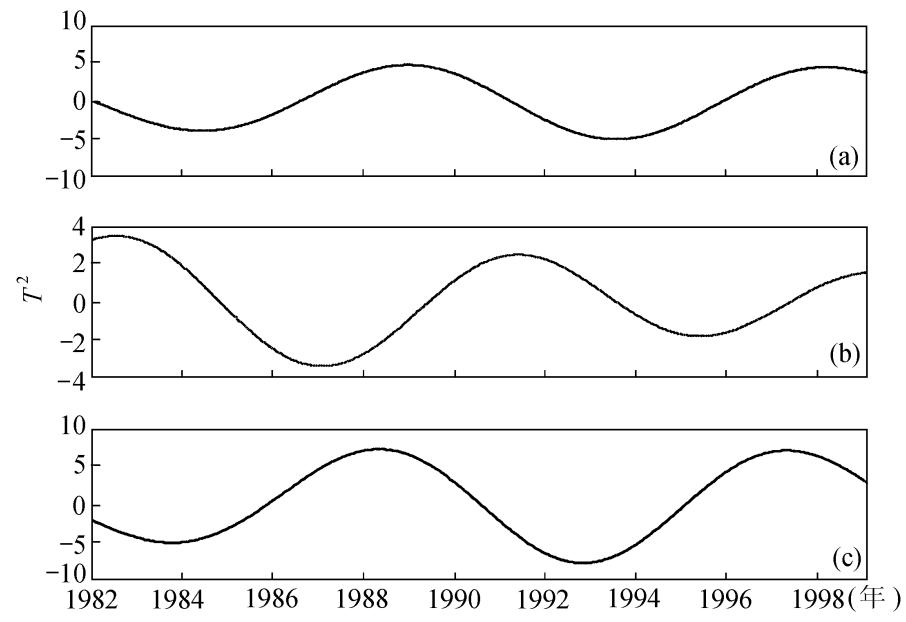

图 7 SSTA 8 10 年平均尺度特征

(a) 南海海域, (b) 赤道东太平洋海域, (c) 赤道西太平洋海域

\section{3 结论}

从前面的讨论可知, 南海与赤道太平洋地区海表温度之间在不同的周期尺度上具有十分密切 的关系. 发生在赤道东太平洋的厄尔尼诺与拉尼娜事件, 对南海 SST 的影响是很强的, 这体现在 南海 SST 的年际变化上. 在 4 5 年周期尺度上, 南海与赤道东太平洋 SSTA 变化呈同相耦合振荡, 而南海与赤道西太平洋则呈反相振荡. 在 8 10 年周期尺度上, 南海与赤道西太平洋 SSTA 变化呈 同相耦合振荡, 而南海与赤道东太平洋则呈反相振荡. 这说明, 在 4 年周期尺度上, 赤道东太平 洋的温度变化对南海的温度影响较大, 而在 8 年的周期尺度上, 赤道西太平洋的温度变化对南海 温度的作用要明显一些, 可见太平洋 SST 变化作用于南海, 南海对其的响应略微滞后约 5 8 个月. 赤道东太平洋与西太平洋 SSTA 之间在年际的尺度上, 总是呈一种反相变化的特征. 南海与赤道 太平洋表层水温在不同年际尺度上的耦合振荡说明了这种年际振荡具有普遍意义.

致谢 本工作为国家“863”计划(批准号：863-06-05)、国家重点基础研究发展规划(编号: G1990438)和国 家自然科学基金 (批准号: 49606070)资助项目.

\section{参考文献}

1 周发琇, 于慎余, 付 刚, 等. 南海表层水温的低频振荡. 海洋学报, 1991, 13(3): 333 338

2 于慎余, 周发琇, 付 刚, 等. 南海表层水温低频振荡的基本特征. 海洋与湖沼, 1994, 25(5): 546 551

3 钮智旺, 南海表层水温的长周期振荡及其与厄尔尼诺的关系. 海洋学报, 1994, 16(2): 43 49

4 谢 强, 焉利农, 侯一筠, 等. 南沙与暖池海域 SST 的长期振荡及其耦合过程. 海洋与湖沼, 1999, 30(1): 88 95

5 Baliunas S, Frick P, Sokoloff D, et al. Time scales and trends in the central England temperature data (1659 1990): A wavelet analysis. Geophys Res Lett, 1997, 24: 1351 1354

6 Mak M. Orthogonal wavelet analysis: Interannual variability in the sea surface temperature. Bull Amer Meteor Soc, 1995, 76: $2179 \sim 2186$

7 李崇银, 李桂龙. 北大西洋涛动和北太平洋涛动的演变与 20 世纪 60 年代的气候突变. 科学通报, 1999, 44(16): 1765 1769

8 Farge M. Wavelet transform and their applications to turbulence. Annu Rev Fluid Mech, 1992, 24: 395 457

9 Xu J S, Tian J W, Wei E B. The Wavelet transform in wave breaking. Acta Mechanica Sinica, 1998, 14(4): 306 318

10 江明顺, 张爱军. 用小波变换研究赤道西太平洋温度细结构. 海洋学报. 1998, 20(6): 12 20 